\title{
The properties of the modern world and the teacher's awareness
}

\section{KEYWORDS}

awareness, professional-knowledge, teacher, globalization, science, technology
Ayzik Elanit, The properties of the modern world and the teacher's awareness. Kultura - Społeczeństwo - Edukacja nr 1(13) 2018, Poznań 2018, pp. 83-90, Adam Mickiewicz University Press. ISSN 2300-0422. DOI 10.14746/ kse.2018.13.6.

The article discusses the teacher's awareness and professional knowledge, emphasizing the characteristics and changes taking place in the modern world and their influence on teaching. Self-definition of the teacher's consciousness has been developed based on the theory of Illeris (2003. p. 227) as a subjective process, which affects the way the teacher operates and assimilates information in the workplace through social interaction. The article presents refers to the concept of "teacher consciousness" as an interdisciplinary concept that characterizes the challenges of the modern world with an emphasis on the development of science and technology, On this background, the importance of the view of the "big picture" (Khenin, 2007: 36-39) stands out in the development of broad pedagogical awareness in the planning of teachers' training. Teacher awareness is an acquired learning tool that enables cognitive ability to extract raw reality from the interpretation of attitudes and beliefs and may determine the school culture and its affiliation to a traditional or an innovative stream.

\section{Introduction}

The purpose of this article is to review the subject of teacher's awareness and professional knowledge, while emphasizing the characteristics and changes that are taking place in the modern world and their impact on teaching. Research 
studies show that teachers are aware of (Illeris, 2011: 46) and present different types of professional knowledge they should use during the fulfillment of their professional obligations (Kincheloe, 2007: 1-60). The accumulated material may help to change the teacher's work style in school space and to allow the teacher to gain knowledge in the workplace by transforming the existing practical knowledge. Experience indicates that until now teachers in Israel still teach according to the traditional model. Frequently the teachers convey knowledge and the students are required to assimilate it (Goskov, 2016: 70-102). The students of the new generation are required to learn through research, experience, interaction, and collaboration, with emphasis on what interests them and the teachers' task is to plan situations and learning spaces adjusted to the child's development. Therefore, it is important to understand and to learn the teachers' work style and to understand the educational approaches that influence it, in the assimilation of skills, in the improvement of learning, in the use of available research literature, in the integration of theory and practice, in the ability to cooperate with peers at work, in the enrichment of the activities that they perform, in the achievement of successes and failures, and in the ability to cooperate with colleagues at work (Illeris, 2011: 46). All these factors are contained in the teacher's personal space (Clandinin, 2014: 361-385), and are the outcome, to a greater or lesser extent, of the teachers' awareness (Illeris, 2003: 227). Awareness in teaching is one of the most important factors of professionalism, regardless of the model of education (Kincheloe, 2007: 1-60),

\section{Awareness in the literature}

In the accessible literature, there are many different definitions proposed by researchers that represent different disciplines and there is no one agreed-upon theory regarding the concept of 'Awareness' (Chalmers, 1995: 200-219). The Awareness constitutes an essential problem for the scientific perception since it is fundamentally a personal subjective experience, while science relies on objective and external information (Levine, 1983: 354-361). In modern Western philosophy, 'awareness' is defined in the experiential aspect described through the concept of 'qualia', the subjective feeling that we experience as an input of our senses and feelings but limited in thinking (Varela, 1996: 330-349). Modern psychologists define 'awareness' as a cognitive component that enables the absorption of stimuli from the environment and internal stimuli, such as thoughts, emotions, and physical feelings (Bargh, Kazdin, 2000: 347-348), the highest level of human functioning (Sohlberg, 
2000: 135-151). In sociology, consciousness is a viewpoint that represents public attention to a topic, problem, or social, scientific, or political event but limited by the senses and the memory (Sillamy, 1994: 54-55).Current pedagogy defines the awareness as a subjective situation of every person as a person, including the teacher (Clandinin, 2014: 361-385). This is an internal psychological process in which the learner structures meaning for knowledge, skills, emotions, and social interaction and develops broader understanding and ability to cope with the practical life challenges (Illeris, 2003, p. 227). Therefore, the homeroom teachers need to aspire to a clear and communicational determination of roles in the school environment. The consciousness is expressed in action, in all that pertains to people and events (Illeris, 2001, p. 46). This is an important process that helps a person undergo a change and develop (Johnson, 2005: 103-129). The following figure presents the analysis of the different interpretations and the broad spectrum of the concept of 'awareness'.

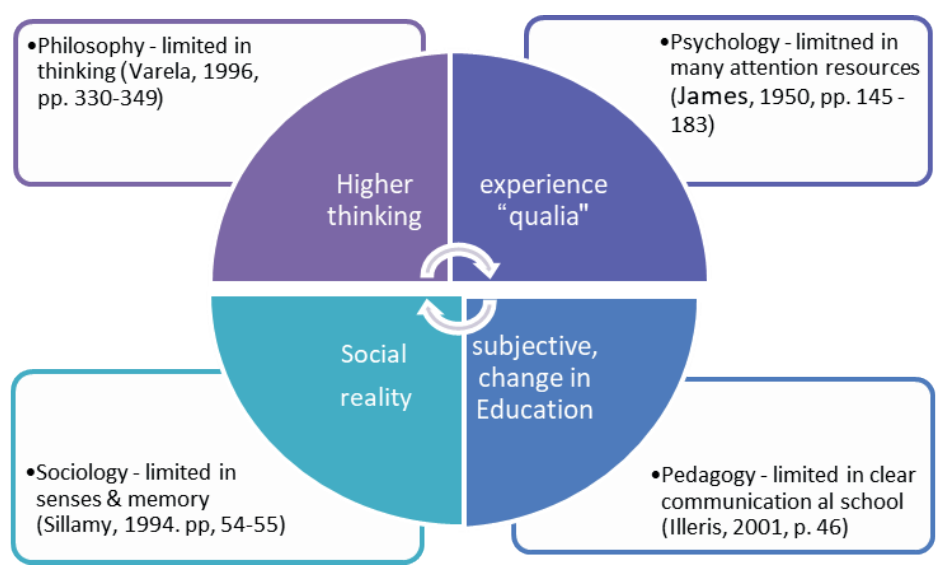

Fig. 1. Conceptual Map of Analysis of Different Interpretations and the Spectrum of 'Awareness' Source: Varela, 1996: 330-349, James, 1950: 145 -183, Sillamy, 1994: 54-55, Illeris, 2001: 46

The definition of the concept of 'Awareness' of the author takes into consideration of the different approaches presented and their characteristics. Consciousness is a basic and internal subjective process that occurs in every person in a situation of awareness and total alertness to what occurs and derives from a personal and social need. This is an instrument that can be acquired and that enables a change in the patterns of the behavior. As the person develops this instrument, his ability of action improves. The main characteristics in the process of the consciousness in the person are the following: 
1. Focusing attention on the first information absorbed in the senses.

2. Subjective interpretation of the objective reality based on: (1) cognitive knowledge and skills; (2) emotional - feelings, thoughts, experiences, memories, and emotions, and (3) social - interaction with the environment.

3. Self-controlling through storage in the long-term memory and using tools for the in-depth understanding and actions of response of future experiences.

On the basis of the collected literature, a self-definition of the teacher's consciousness has been developed. Illeris (2003) used the concept and found that consciousness is a subjective process occurring in the teacher, which influences the way he acts and assimilates information in the workplace, which expresses itself not only in the didactic process but also in the engagement A teacher in the acquisition of knowledge, skills, emotions, social interaction developing the ability to see and perform educational tasks with tangible effects. They are extremely important because of the changes in the modern world.

\section{Changes and challenges in the world today versus the importance of learning for the teacher}

The processes of globalization began in the first half of the 19th century and grew stronger in the second half of the 20th century. The main factors for this are communicational technological developments, scientific development, and economic-political developments. In essence, the relationship between the global and the local is a process of natural creation in which local developments depend on developments in other societies in distant parts of the world that threaten the spiritual and equal world of humanity (McGrew, Lewis 1992: 315), While having an impact on the awareness of every human being. In this changing space reality, new human needs, required for the young generation, the employment of multiple roles during the professional life, and the importance of the acquisition of suitable learning skills arise. Seeing them more aware by:

1. Communication, cooperation, and language (Vygotsky, 2004: 126).

2. Handling information (Martin, Madigan, 2006: 80).

3. High order thinking and self-learning (Harpaz, 2009: 38-44).

4. Use of computerized communication instruments, ethics, and protection online (Martin \& Madigan, 2006: 49).

5. Personal development (Shenar, 2010: 31).

6. Skills for life and career (Salpeter, 2003: 17-26). 
The new reality is responsible for the positive and negative implications in all areas of life around us. The implications of globalization on education are expressed in the 'economization' of the thinking and the educational action. Education is perceived as an economic resource intended for the improvement of competitiveness in the global economy. The success in the international achievement tests (PISA, TIMSS, etc.) becomes the main goal of the educational system at the expense of the humanistic and artistic contents (Hanin, 2007: 36-39). The point is to educate young people so that they can manage themselves and in school and life. To this need is the teacher's awareness and education (Aloni, 2004: 41-49). The modern changes alter from the foundation the learning conditions and personal space of the teachers and naturally influence the teachers' consciousness, new ways of learning focus more and more on the learner and on the active learning processes, the flexible structure of the studies, contents adjusted to the social-cultural, economic, and cultural processes of change that invite engagement in actual issues and dilemmas that develop environmental-social consciousness, all this with the integration of technology in the processes of teaching-learning-assessment (Vidislavsky et al., 2011: 1-16).

Some maintain that the teacher's thinking is influenced by the world of science and technology to which he is exposed during his life, training, and experience. Teachers tend to adopt new ways of teaching in the class, if these are commensurate with their personal epistemological perceptions (Clark, Peterson, 1986: 255-296). The scientific technological development brought with it a background of unquiet that characterizes the educational system and ambivalence. The concept of knowledge, the curricula, the school architecture, and the learning assume a different meaning. In a period of the lack of stability, diversity, and heterogeneity in academic, cultural, and socioeconomic terms, teaching and education become a complicated and demanding tasks for the teacher (Hargreaves, Fink, 2006: 105), However, the borders between all the sciences of the social sciences, the behavioral sciences, and the education sciences are rigid, and therefore they are called multidisciplinary. It is also possible that overlap will be created among them. Education aspires to be an applied multidisciplinary area of knowledge, and therefore it cannot disconnect from facts. Since knowledge is multidisciplinary and draws from different areas of knowledge, in the setting of positions in education there are considerations from different areas (Pasternak, 2002: 1-12). On this background, the importance of the view of the 'big picture' is prominent (Hanin, 2007: 36-39) in the development of broad pedagogical awareness in the planning of the teachers' teaching. 


\section{The teachers' consciousness as a basis for professional performance}

Many researchers agree about the importance of consciousness in the processes of thinking in general and its role in the practice of teachers and developed different models for the purpose of the improvement of the quality of the teaching. model of extended professionality (Hoyle, 1975: 318), Critical pedagogy maintained that the way to social change lies in the development of consciousness (Shor, Freire, 1990: 105-126), Kincheloe (2007: 1-60) presents a model of post-positive training that shows that teachers build in actuality their practice according to critical knowledge and personal and social consciousness. According to the model of learning of Illeris (2011: 46), the importance of consciousness among teachers is expressed during their action in the school environment as a result of an internal psychological process in which they structure meaning into knowledge, skill, emotions, and social interaction simultaneously and develop a broad understanding and ability to cope with the practical challenges of life. The starting point of Illeris is that the teachers' awareness undergoes a process of change through what the teacher chooses to give attention. Thus, the focus on internal situations is an important component, a component that helps the person undergo a change and develop into a person who cares for and cultivates the 'self', the other, and the environment. In addition, teachers hold an interaction with an environment that includes other people, a certain culture, technology in a global and rapidly changing world that proposes many possibilities for learning without limitation (Illeris, 2003: 227) and in the modernity of the present era we are aware of the high frequency of the process of interaction and the power of social influence (Gergen, 1994: 93-143).

It is possible to summarize that the teachers' consciousness appears in the professional literature in a number of ways and all the researchers agree about the importance of consciousness for teachers and its critical influence in the practical work of the teacher in the school environment. Therefore, the author broadens the concept of "consciousness" and defines the concept of "teachers' consciousness" as follows. Teachers' consciousness is an interdisciplinary concept of the teacher, which characterizes the challenges of the modern world with emphasis on the development of science and technology that influence the teacher. This is an acquired learning tool that enables cognitive ability to extract a raw reality from the interpretation of attitudes and beliefs and the ability to act effectively and efficiently in the school. The process of the development of the consciousness through the three stages of FSS: 
1. Focusing - The teacher knows what he does.

2. Subjective Interpretation of the objective reality - The teacher understands why he doing.

3. Self-Controlling - The teacher is responsible for his knowledge and his actions.

\section{Resume}

The author defines the teachers' consciousness as an increase in the teacher's ability to think, consider, understand, and solve problems. The development of the consciousness among teachers entails therefore the development of high order thinking skills, techniques and mental abilities through the use of reflection and meta-cognition, intended to guide the process of thinking for the purpose of self-control. In essence, the desired teacher is the person who knows to address his knowledge. The increase of the teachers' awareness of the processes of thinking and doing, as a result of the internal and external events around them, may help teachers map their abilities, needs, and expectations, understand the factors of their behavior, plan and define for themselves goals commensurate with the requirements. The awareness grants the teachers an opportunity to take responsibility over the knowledge and thus may change the school experience and its space.

\section{References}

Aloni N. (2004). Humanistic education: theory into practice. "Education and Its Environs: Annual Journal of the HaKibbutz College of Education" 26, pp. 41-51.

Bargh J., Kazdin A.E. (2000). Encyclopedia of Psychology, vol. 1. Washington, DC. pp. 347-348.

Chalmers D.J. (1995). Facing up to the problem of consciousness. "Journal of Consciousness Studies" 2.3, pp. $200-219$.

Clandinin D.J. (2014). Personal practical knowledge: a study of teachers' classroom images. "Journal of Curriculum Inquiry" pp. 361-385.

Clark C.M., Peterson P.L. (1986). Teachers thought processes. [In:] M.C. Wittrock (ed.). Handbook of Research on Teaching. New York, pp. 225-296.

Gergen K.J. (1994). Realities and Relationships: Soundings in Social Constructionism. Cambridge. Giroux H.A. (1983). Theory and Resistance in Education. South Hadley.

Giroux H.A. (2007). Introduction: Democracy, Education, and the Politics of Critical Pedagogy. [In:] P. McLaren \& J. L. Kincheloe, Critical Pedagogy: Where Are We Now? (pp. 1-5). New York. 